The Federal Reserve BanK of Kansas City ECONOMIC RESEARCH DEPARTMENT

\title{
Decomposing the Declining Volatility of Long-Term Inflation Expectations
}

Todd E. Clark and Troy Davig

February 2009

RWP 09-05 


\title{
Decomposing the Declining Volatility of Long-Term Inflation Expectations
}

\author{
Todd E. Clark and Troy Davig*
}

February 2009

RWP 09-05

\begin{abstract}
The level and volatility of survey-based measures of long-term inflation expectations have come down dramatically over the past several decades. To capture these changes in inflation dynamics, we embed both short- and long-term expectations into a mediumscale VAR with stochastic volatility. The model documents a marked decline in the volatility of expectations, but also reveals a shift in the factors driving their movement. Throughout the 1980s and early 1990s, the majority of the variance in long-term expectations were driven by 'own' shocks. Beginning in the mid-1990s, however, the factors explaining the variance of long-term expectations began shifting amidst an overall decline in volatility. At the end of the sample in 2008, innovations to measures of inflation and output account for the majority of the remaining low-level of volatility in long-term expectations. We document a shift in monetary policy towards more systematic behavior that precedes the shift in the factors driving long-term expectations.
\end{abstract}

Keywords: Survey-based inflation expectations, stochastic volatility, Bayesian econometrics

JEL Classification: E31, E32, E52

\footnotetext{
* Economic Research Department, 1 Memorial Drive Kansas City, Missouri 64198. Telephone: (816) 881-2575 (Clark) and (816) 881-2701 (Davig). Fax: (816) 881-2199. Email: todd.e.clark@kc.frb.org and troy.davig@kc.frb.org. The views expressed in this paper are those of the authors and do not necessarily reflect the views of the Federal Reserve Bank of Kansas City or the Federal Reserve System.
} 


\section{Introduction}

The level and volatility of survey-based measures of long-term inflation expectations have come down dramatically over the past several decades. In the U.S., this is apparent by examining survey measures that report expected average inflation over the next 10 years. For example, survey-based expectations of long-term CPI inflation varied between 5.5 and 4 percent from 1982 to 1990. In comparison, they varied between 2.3 and 2.6 percent from 2000 to 2008 .

This paper documents changes in the factors that account for the reduced variability of long-term inflation expectations. We do so by embedding both short- and longterm expectations into a medium-scale VAR with stochastic volatility. The model captures the marked decline in the volatility of expectations, but also reveals a shift in the factors driving movements in long-term expectations. Throughout the 1980s and early 1990s, the majority of the variance in long-term expectations was driven by 'own' shocks. That is, innovations to long-term expectations itself were the primary factor explaining their movement. Beginning in the mid-1990s, however, expectations gradually became more responsive to movements in actual inflation. This shift occurs amidst an overall decline in the volatility of expectations and inflation. At the end of the sample in 2008, volatility in long-term expectations is at it lowest level in the sample and shocks to actual inflation account for the majority of its volatility. We document a shift in monetary policy towards more systematic behavior that precedes the shift in the factors driving long-term expectations.

The set of variables in the VAR include measures of short- and long-term expectations, inflation, a measure of real economic activity and the federal funds rate. We focus primarily on two versions of the model. The first is a conventional VAR and the other incorporates stochastic volatility. The purpose of estimating the conventional VAR is to assess whether the set of variables and identification strategy captures the salient linkages among expectations, inflation and monetary policy. In this setting, a shock to monetary policy that raises the federal funds rate generates a decline in short-term expectations and a more modest decline in long-term expectations. Also, real economic activity and inflation both modestly fall with a three to four quarter lag. These responses are consistent with the results from the VAR in Leduc, Sill and Stark (2007), which embeds short-term inflation expectations from the Livingston Survey into a relatively standard VAR.

Embedding expectations into a VAR also allows us to analyze shocks directly to either short- or long-term inflation expectations. We prefer to think of these shocks as unforecastable movements in expectations resulting from changes in 'omitted' fundamentals, rather than pure sunspot or expectational types of shocks. ${ }^{1}$ For example,

\footnotetext{
${ }^{1}$ This interpretation is the same as Leduc, Sill and Stark (2007) and Mehra and Herrington (2008).
} 
central bank communication or movements in certain commodity futures' prices may, in some instances, affect private sector expectations of inflation. In practice, incorporating all such potential factors in a suitable framework is infeasible. In the VAR framework, however, variance decompositions and impulse response analysis are readily available to study the impact of shocks to expectations. We find that a shock to long-term expectations produces a significant, commensurate increase in short-term expectations and inflation. In response, monetary policy persistently raises the federal funds rate for several periods. The cumulative increase in the federal funds rate is more than one-for-one with respect to the increase in inflation, as well as to the increase in expected inflation. In contrast, a shock to short-term expectations does not elicit nearly as strong a response from monetary policy. Leduc, Sill and Stark (2007) report that a shock to short-term expectations in the 1979-2001 period causes an aggressive monetary tightening that raises the real federal funds rate, defined as the nominal federal funds rate minus short-term inflation expectations. Using this same measure and a sample of 1982-2008, we find that the real federal funds rate rises in response to a shock to long-term expectations, but not short-term expectations.

In the VAR model with stochastic volatility, we include the same set of variables and use the same identification strategy as in the standard VAR. The benefit of allowing stochastic volatility is that it captures the substantial decline in volatility over the first part of the sample. In the latter portion of the sample, the volatility of the innovations for every variable, except inflation (total or headline), remains relatively low. The volatility of the inflation innovation, however, rises to its highest level near the end of the sample. For long-term expectations, there is a substantial decline in the volatility of its innovation, but of greater interest is the shift in the variance decompositions for long-term expectations. Until the mid-1990s, about 75 percent of the variance in long-term expectations was attributable to own shocks. In 2008, the own shock contribution fell to 25 percent, whereas the contribution from actual inflation rose to over 50 percent.

Our stochastic volatility approach in this paper connects to the growing literature that uses Bayesian methods to estimate time-varying parameter models with stochastic volatility. For example, U.S. studies such as Cogley and Sargent (2005), Primiceri (2005), and Cogley, Primaceri, and Sargent (2008) allow time-varying parameters and stochastic volatility in trivariate macroeconomic VARs (containing inflation, a measure of economic activity, and a short-term interest rate), for the purposes of assessing changes over time in macroeconomic dynamics. Benati and Surico (2008) consider a similar four-variable model (augmented to include money growth), to assess the sources of the decline in inflation's predictability. In another example, Canova and Gambetti (2008) estimate a time-varying parameter VAR with stochastic volatility for a four-variable model that includes short-term inflation expectations, to assess the role of expectations in the declining volatility of the U.S. economy. Our analysis uses estimation methods similar to these papers, except that we hold the autoregres- 
sive coefficients in the VAR constant in our shorter, mostly Great Moderation-period sample and include both short- and long-term expectations.

The paper is organized as follows: Section 2 describes the survey measures of expected inflation. Section 3 describes and reports the results from a benchmark VAR. Section 4 expands the VAR to include stochastic volatility. Section 5 performs some robustness checks, such as disaggregating inflation into sub-components and allowing for time-varying parameters. Section 6 concludes.

\section{Survey-Based Inflation Expectations}

To incorporate both short- and long-term expectations of inflation into our analysis, we must use expectations data from two sources. The first is the Federal Reserve Bank of Philadelphia's Survey of Professional Forecasters (SPF). ${ }^{2}$ Respondents to this survey report both 1-year and 10-year ahead forecasts for CPI inflation. The 1-year forecast in period $t$ refers to a forecast of inflation from $t+1$ through $t+4$, made in the middle of quarter $t$. The 10-year ahead forecast is a projection of the average inflation rate over the next 10 years. For each expectation measure, we use the median forecast from the distribution of respondents.

The SPF 10-year forecast series is only available starting in 1991:Q4, so to extend the sample we splice it to a conceptually similar series we construct from the Blue Chip Economic Indicators. Starting in 1979, Blue Chip surveys in the spring and fall of each year (March and October, except for some of the early long-run surveys) include the Long-Range Consensus U.S. Economic Projections. These projections are comparable to the SPF forecasts primarily because each survey draws from a pool of professional economists. ${ }^{3}$ Each respondent reports a forecast for 1-5 and 6-10 years ahead, which we average to obtain a 10-year ahead forecast. To construct a quarterly series, we linearly interpolate the Blue Chip series into a monthly frequency and then select the observations from the months when the SPF survey is due (February, May, August, and November). As a check of this procedure, we find that since 1991 the long-term forecasts we construct from the Blue Chip forecasts are very similar to the SPF 10-year forecasts.

Also, each survey-based measure refers to CPI inflation, so we use the correspond-

\footnotetext{
${ }^{2}$ The SPF data is available from the Philadelphia Fed's web site.

${ }^{3}$ Long-term inflation expectations of consumers are also available over longer sample periods. For example, the Michigan survey provides long-term expectations back to 1975, although with many months prior to 1990 missing. Consumer-based expectations, however, are often found to be biased and have been shown to revert to the expectations of professional forecasters (see Carroll (2003)). Thus, combining consumer-based survey measures with professional forecasters is likely to be misleading.
} 
ing measure of actual CPI inflation in each model. ${ }^{4}$ The sample of all data is at a quarterly frequency and runs from 1981:Q3 through 2008:Q2; after allowing for four lags, our estimation sample starts with 1982:Q3. ${ }^{5}$

\section{VAR Analysis}

As a starting benchmark, we estimate a five-variable VAR that includes both shortand long-term expectations. The approach to embedding inflation expectations into the VAR and identification strategy is similar to Leduc, Sill, and Stark (2007), who add eight-month ahead inflation expectations from the Livingston Survey to an otherwise conventional macroeconomic VAR. We build on their approach by incorporating both short- and long-term expectations into the model. ${ }^{6}$ Also, our sample ends in the middle of 2008, instead of 2001. In the next section, we extend the model to allow for stochastic volatility and time-variation in the contemporaneous response coefficients.

The model is a standard VAR,

$$
\begin{aligned}
y_{t} & =X_{t}^{\prime} B+A^{-1} \Sigma \varepsilon_{t}, \\
X_{t}^{\prime} & =I_{n} \otimes\left[1, y_{t-1}^{\prime}, \ldots, y_{t-k}^{\prime}\right], \\
\operatorname{Var}\left(\varepsilon_{t}\right) & =I_{n},
\end{aligned}
$$

where $y_{t}=\left[S_{t+40 \mid t}, S_{t+4 \mid t}, \pi_{t}, x_{t}, r_{t}\right]^{\prime}$, so $n=5$. The variables are as follows: $S_{t+k \mid t}$ denotes survey-based measures of expected average inflation over the next $k$ quarters, $\pi_{t}$ is CPI inflation, $x_{t}$ is the Chicago Fed National Activity Index (CFNAI), and $r_{t}$ is the nominal federal funds rate. We estimate the model with four lags.

For the measure of real economic activity, we use the CFNAI because of its broad coverage, strong contemporaneous correlation to real output and reduced sensitivity to the types of real-time data issues and revisions that plague the use of real gross domestic product in VARs. ${ }^{7}$ Of course, other alternatives are available, such as industrial production, the unemployment rate or real GDP itself. However, industrial

\footnotetext{
${ }^{4}$ For the months with Blue Chip data from 1979:Q4 to 1982:Q4 and 1983:Q4, Blue Chip provides expectations for the GNP deflator, but not the CPI. Because the CPI forecasts and deflator forecasts are very similar (sometimes the same, sometimes very slightly different, without a consistent gap) in the few years in which CPI forecasts first become available, for these early source observations we fill in the CPI forecasts with deflator forecasts.

${ }^{5}$ The timing of our estimation sample reduces the importance of methodological inconsistencies with historical CPI data. Historically, the biggest methodological break in the CPI is the January 1983 change to the rental equivalence basis for housing costs. Our sample only includes two observations from 1982, so the methodological break will not have any impact on the final results.

${ }^{6}$ See also Choy, Leong, and Tay (2006) and Mehra and Herrington (2008).

${ }^{7}$ The CFNAI is the first principal component extracted from 85 separate economic series describing the real economy and originates from Stock and Watson (1999).
} 
production covers only roughly 20 percent of the economy and is subject to data revisions. The unemployment rate is a broad indicator and rarely has meaningful revisions, but is a lagging indicator of economic activity. Real GDP is often subject to nontrivial data revisions. For these reasons, the CFNAI is a viable alternative and although the CFNAI is influenced by data revisions, a revision to any one particular underlying series is unlikely to have a meaningful impact on the headline index. Also, using the CFNAI fits into the factor-augmented VAR literature that argues combining factor analysis with standard VAR analysis improves identification of the monetary policy transmission mechanism. ${ }^{8}$

To identify the effects of shocks to each variable, we use a recursive identification scheme with the following ordering: long-term expectations, short-term expectations, CPI inflation, the CFNAI, and the federal funds rate. ${ }^{9}$ Survey measures are placed first due to the timing of when the Survey of Professional Forecasters asks forecasters to submit their responses. Typically, the deadlines are in the middle of the second month of the quarter, which means forecasters will have seen, at best, CPI data on only the first month of the quarter. Recently, the survey deadlines are somewhat earlier, implying forecasters would not have any CPI inflation data within the quarter that they are submitting their forecast. For example, the 'True Deadline Date' given by the SPF for 2008:Q1 is February 7, 2008. The Bureau of Economic Analysis released the CPI for the month of January on February 20, 2008. In this case, forecasters would not have seen even one month of data for the quarter in which they are submitting their forecast. For the portion of the sample using the Blue Chip Long-Range forecasts, survey respondents will have typically observed the first month of the quarter's data. In addition, there is a substantial delay between when the forecast is made and the forecast horizon. For example, the March 2008 Blue Chip survey requested forecasts for a 10 year horizon beginning in 2010. Given this long of a lag, a survey respondent is unlikely to revise such a long-term forecast in response to even a few months of data. In general, the timing and horizon of both surveys suggest that innovations within a quarter will not contemporaneously affect survey-based expectations of future inflation.

Long-term expectations are ordered before short-term expectations since a forecaster revising his/her long-term forecast, for whatever reason, will also likely revise the short-term forecast. In contrast, a forecaster suddenly revising his/her short-term forecast may be less likely to revise the long-term forecast. Inspecting the SPF data at the level of the individual forecasters supports this ordering. For example, ten of the longest-participating forecasters in the SPF revise their one-year ahead forecast in almost every quarter. In contrast, they revised their long-term forecast much less frequently, only 56 percent of the time.

\footnotetext{
${ }^{8}$ For example, see Bernanke, Boivin and Eliasz (2005).

${ }^{9}$ We average the monthly values for inflation, the federal funds rate, and the CFNAI, to form the quarterly measures.
} 
For the remaining variables, CPI inflation is before the CFNAI. However, the qualitative results are insensitive to whether this ordering is reversed. The federal funds rate is ordered last, since the Federal Reserve can freely adjust the rate in response to movements in observable data.

Of primary interest is the impact shocks to expectations have on the other variables and how monetary policy responds. Again, we view these shocks as unforecastable movements in expectations resulting from changes in 'omitted' fundamentals, rather than pure sunspot or expectational types of shocks. Figure 1 gives the impulse responses for each orthogonalized shock with $70 \%$ confidence bands. A shock to long-term expectations (responses shown in first column) generates a persistent rise in both short- and long-term expectations. Both variables rise on impact by roughly 10 basis points before gradually decaying. Inflation initially rises by about 25 basis points, but then declines to insignificant levels in the second period. Monetary policy responds by aggressively tightening for several quarters. The federal funds rate rises more than one-for-one with the increase in inflation, as well as to the increase in expected inflation. The federal funds rate rises at its peak by about 25 basis points three periods after the shock. Thus, the cumulative response of the federal funds rate is substantially larger than the cumulative rise in either CPI inflation or inflation expectations.

A shock to short-term expectations (responses shown in second column) also generates a rise in long-term expectations and generates a temporary rise in inflation. In response, monetary policy temporarily tightens, but less aggressively than in response to a shock to long-term expectations. Apart from the behavior of long-term expectations, our estimates have similarities to those of Leduc, Sill, and Stark (2007) for the 1979-2001 period. In a VAR with short-term expectations, they show a rise in expectations, as taken from the Livingston Survey, leads to a temporary monetary tightening, followed by a decline in inflation and rise in unemployment. Figure 1 shows a similar pattern with one important difference. Leduc, Sill and Stark (2007) show that a shock to short-term expectations in the 1979-2001 period causes an aggressive monetary tightening that causes a rise in the real federal funds rate, defined as the nominal federal funds rate less short-term inflation expectations. Using this same measure, Figure 1 indicates that the real federal funds rate rises in response to shocks to long-term expectations, but not short-term expectations. That is, the path of the fed funds rate minus short-term expectations is negative for the first few quarters following the shock to short-term expectations. In contrast, the real federal funds rate rises following a shock to long-term expectations.

In light of our goal of explaining the reduced volatility of long-run inflation expectations, the responses of expectations to shocks to inflation and economic activity (the CFNAI) are also of interest. A shock to inflation (responses shown in third column) causes both short- and long-term expectations to rise. The rise in short-run expectations dies out relatively quickly compared to long-term expectations, although 
the differences are probably not statistically significant. In response, monetary policy eases and economic activity declines. This shock appears to be capturing primarily 'supply side' disturbances. An innovation to the CFNAI (responses shown in fourth column) is associated with increases in actual inflation and inflation expectations. The rise in inflation exceeds the rise in short-term expectations, which in turn exceeds the increase in long-term expectations. Accordingly, this shock seems to capture textbook 'demand side' disturbances.

Finally, a shock raising the federal funds rate (responses shown in last column) eventually lowers short- and long-term expectations after about one year. Inflation and economic activity also decline temporarily for a few quarters following the shock, though the level of significance is negligible. The responses are qualitatively similar to those of Leduc, Sill, and Stark (2007) for 1979-2001, although with more modest responses of expectations, which likely reflects the difference in the sample period and data.

\section{A VAR with Stochastic Volatility}

Having established that a conventional VAR in the variables of interest reasonably captures the expected linkages among inflation expectations, inflation, economic activity, and monetary policy, we now turn to a version of the model generalized to allow stochastic volatility, in the interest of accounting for the sources of the reduced volatility of long-term inflation expectations. We first describe the model and estimation procedures, then present our baseline results, and then show our results to be robust to some generalizations of the model.

\subsection{Model Specification}

A VAR with stochastic volatility - that is, a model that incorporates time variation in the variance-covariance matrix of innovations - allows us to to distinguish changes in the contemporaneous relationships among the variables from changes in the volatility of the innovations. The structure is similar to Primiceri (2005), except we continue to restrict the VAR coefficients on the lagged variables to be constant. We impose this restriction primarily due to computational feasibility and also because the sample is relatively short (i.e., about 26 years), so we need to limit the number of free parameters. Also, Primiceri (2005) and Canova, Gambetti and Pappa (2007) stress the importance of time variation in the variance-covariance matrix of the innovations over time variation in the VAR coefficients for explaining U.S. data. ${ }^{10}$ These

\footnotetext{
${ }^{10}$ Sims and Zha (2006) also emphasized the importance of volatility changes compared to coefficient changes.
} 
papers reach this conclusion despite using much longer samples, over which changes in monetary policy and other structural shifts suggest that time-varying parameters may be more relevant. Nonetheless, in our robustness analysis we show that our results also hold in a smaller model with both time-varying parameters and stochastic volatility.

The model specification is as follows

$$
\begin{aligned}
y_{t} & =X_{t}^{\prime} B+A_{t}^{-1} \Sigma_{t} \varepsilon_{t}, \\
X_{t}^{\prime} & =I_{n} \otimes\left[1, y_{t-1}^{\prime}, \ldots, y_{t-k}^{\prime}\right], \\
\operatorname{Var}\left(\varepsilon_{t}\right) & =I_{n},
\end{aligned}
$$

where

$$
A_{t}=\left[\begin{array}{cccc}
1 & 0 & \cdots & 0 \\
a_{21, t} & 1 & \ddots & \vdots \\
\vdots & \ddots & \ddots & 0 \\
a_{n 1, t} & \cdots & a_{n n-1, t} & 1
\end{array}\right], \quad \Sigma_{t}=\left[\begin{array}{cccc}
\sigma_{1, t} & 0 & \cdots & 0 \\
0 & \sigma_{2, t} & \ddots & \vdots \\
\vdots & \ddots & \ddots & 0 \\
0 & \cdots & 0 & \sigma_{n, t}
\end{array}\right]
$$

and $y_{t}=\left[S_{t+40 \mid t}, S_{t+4 \mid t}, \pi_{t}, x_{t}, r_{t}\right]^{\prime}$. The vectors of parameters follow random walk processes

$$
\begin{aligned}
a_{i, t} & =a_{i, t-1}+v_{i, t}, \quad i=2, \ldots, n \\
\log \sigma_{t} & =\log \sigma_{t-1}+e_{t}
\end{aligned}
$$

where $a_{i, t}$ is the vector containing the non-identity elements in row $i$ of the lower triangle of $A_{t}$ and $\sigma_{t}$ is the vector including the primary diagonal of $\Sigma_{t}$. Also, $v_{i, t} \sim$ $N\left(0, Q_{i}\right)$ and $e_{t} \sim N(0, S)$, where $S$ is diagonal.

We estimate the model using Bayesian methods (a Metropolis-within-Gibbs sampler) and primarily use the approach in Cogley and Sargent (2005), except that we allow the elements of $A$ to be time varying. ${ }^{11}$ And, more importantly, in our case the estimation procedure is simplified by the constancy of the VAR coefficients, $B$. More specifically, in our Markov chain Monte Carlo algorithm, conditional on the draw of $A_{t}$ and $\Sigma_{t}$, the VAR coefficients are estimated with a flat prior, which is effectively equivalent to GLS estimation (i.e., the posterior mean and variance are effectively equivalent to the GLS estimates; in the Gibbs algorithm, we then take a draw from a normal distribution with mean and variance equal to the posterior mean and variance). Conditional on the VAR coefficients and $\Sigma_{t}$, the elements of $A_{t}$ are estimated as in Primaceri (2005). Finally, conditional on the VAR coefficients and $A_{t}$, the log volatilities are estimated as in Cogley and Sargent (2005).

\footnotetext{
${ }^{11}$ Primaceri (2005) and Benati (2008) pursue a similar estimation strategy.
} 
In the case of the stochastic volatility estimates $\left(A_{t}\right.$ and $\left.\Sigma_{t}\right)$, we follow Cogley and Sargent (2005) and Primiceri (2005) in setting key elements of the priors from estimates of a VAR from a training sample of 10 years of data. In this training sample, econometric estimates from Kozicki and Tinsley (2001) proxy for long-term expectations and short-term expectations are partly from SPF forecasts of CPI inflation (which start in 1981) and partly from SPF forecasts of inflation in the GNP deflator (which go back to 1970). Posterior estimates are from a sample of 5,000 draws, obtained by first generating 10,000 burn-in draws and then saving every fifth draw from another 25,000 draws.

\subsection{Volatility Estimates}

Figure 2 reports the posterior medians for two measures of the time-varying residual standard deviations. One measure reports the structural measure, given by

$$
\sigma_{j, t}=\left(\iota_{j}^{\prime} \Sigma_{t} \Sigma_{t}^{\prime} \iota_{j}\right)^{.5}
$$

where $\iota_{j}$ is a $n \times 1$ vector with a one in the $j^{\text {th }}$ element and zeros in the remaining elements. The other measure of volatility in Figure 3 reports the reduced-form instantaneous deviation, given by

$$
u_{j, t}=\left(\iota_{j}^{\prime} A_{t}^{-1} \Sigma_{t} \Sigma_{t}^{\prime} A_{t}^{\prime-1} \iota_{j}\right)^{.5} .
$$

This measure can change either due to a change in structural volatility or a change in the contemporaneous correlation between variables.

Changes in the difference between the reduced-form and structural residual standard deviations reflect variation in $A_{t}$. For many of the variables, the difference is quite stable, suggesting changes in the residual standard deviations is driven by heteroscedasticity of the innovations, rather than changes in their contemporaneous correlation.

As Figure 2 indicates, the volatility of shocks to long-term expectations has varied, but exhibits a pronounced decline over the sample period (under our identification scheme, which places long-run expectations first, there is no difference between the reduced-form and structural measures). The volatility of long-term expectations declines throughout the sample despite a marked increase in the volatility of CPI inflation, which is higher at the end of the sample than at the beginning. The rise in volatility for inflation at the end of the sample reflects volatile movements in food and energy prices. ${ }^{12}$ Volatility in the innovations to short-term expectations and the

\footnotetext{
${ }^{12}$ The next section reports estimates from an alternative specification that disaggregates CPI inflation between core and food-energy components.
} 
federal funds rate also trended down in the first few decades of the sample and have only modestly risen over the past five years.

Also of interest is the relative rates of change in the volatilities among the variables. Dropping most quickly over the first part of the sample is the volatility in the innovation to the federal funds rate, with the structural standard deviation declining from over 1.00 percent at the beginning of the sample to under .25 percent by 1991. This decline certainly reflects the Federal Reserve's movement away from targeting non-borrowed reserves to adjusting the federal funds rate in a more systematic way. For the remaining variables, volatility can roughly be described as declining by about 50 percent from the beginning of the sample to the early 1990s. This period is somewhat remarkable, given the structural shocks for each variable are orthogonal, so there is no a priori reason to suppose shifts in volatility should be correlated. In addition, the volatility of the innovation to long-term expectations continues to trend down despite the sharp rise in the volatility of the inflation innovation late in the sample.

\subsection{Decomposing the Decline in Expectations Volatility}

To more completely assess the sources of the decline in the volatility of long-term expectations, we rely on variance decompositions. For each period $t$ in our sample, we compute a variance decomposition using the variance-covariance matrix of residuals implied by $A_{t}$ and $\Sigma_{t}$ (and the time-invariant VAR coefficients $B$ ). ${ }^{13}$ Conditional on parameter values in 1982:Q3, Table 1 reports that at a one-year horizon, 75 percent of the variance of long-term expectations is attributable to the orthogonal innovation to long-term expectations itself - that is, movements in its own shock (i.e. $\left.\sigma_{1, t}\right)$. This share is 63 percent after two years and then falls to 49 percent after five years. The contributions coming from actual inflation and short-term expectations are modest at all horizons. The contribution from innovations to the federal funds rate is also modest at short horizons, but accounts for 21 percent of the variance at a horizon of five years.

Table 2 reports the same statistics conditional on 2008:Q2 parameter values. In contrast to early in the sample, the variance of long-term expectations attributable to own shocks at a one-year horizon is only 33 percent, a sharp decline compared to the 75 percent at the start of the sample. Further out, the shares decline to 24 percent after two years then to 17 percent after 5 years. The bottom line is that the share of the variance attributable to own shocks for long-term expectations has fallen dramatically over the past twenty-five years.

\footnotetext{
${ }^{13}$ Specifically, for each posterior draw, we compute a decomposition for period $t$. We report the posterior mean estimates of the variance shares for each variable, expressed in percentage terms.
} 
Unlike the decline in the volatility of the innovation to long-term expectations, the shift in its variance shares did not occur gradually over the sample period. To illustrate, Figure 3 shows the variance shares at a two-year horizon for each date. The shift towards inflation as a driver of long-term expectations begins in the late 1990s, whereas the decline in volatility began in the mid-1980s.

To verify that the changes in average shares shown in Table 2 and Figure 3 are significant, Table 3 reports the posterior probabilities of a change in the variance share comparing the beginning and end of the sample. ${ }^{14}$ Specifically, entries in the table are the posterior probabilities that the variance shares for each variable in 2008:Q2 are greater than the corresponding share in 1982:Q3 (i.e., the percentage of draws in which the variance share in 2008:Q2 is greater than in 1982:Q3). For example, the probability that CPI inflation accounts for a greater share in the variance of long-term expectations in 2008:Q2 than in 1982:Q3 is .991 at a one-year horizon and .983 at a five-year horizon. These numbers reinforce the message from Figure 3. In general, the share of the variance attributable to movements in inflation for each variable rose substantially, but is most pronounced for inflation and inflation expectations. Importantly, the shift in the composition of the factors driving volatility in long-term expectations occurs during the dramatic decline in its volatility.

In general, the changes in the behavior of long-term expectations indicate that they are more tightly linked to observable measures of inflation. That is, do these changes imply long-term expectations are better anchored? In this framework, longterm expectations can be 'anchored' in two ways, either by exhibiting little or no response to movements in other macroeconomic variables or having innovations with low volatility. Since the survey measures of long-term expectations are defined as expected average inflation over the next 10 years, a rise in observable inflation that is expected to persist should have a modest impact on this measure. So a rise in long-term expectations in response to an increase in inflation does not necessarily imply expectations are unanchored. Ideally, we would want to extract an expected forward rate of inflation, such as the 1-year 9-year ahead rate. ${ }^{15}$ If expectations are fully anchored, a forward measure such as this should not respond to current inflation. Such a measure, however, is not available. Empirically connecting the survey-based measures of long-term expectations to macroeconomic observables is then clearly desirable, since explaining their movement can reassure policymakers that they have not become disconnected or 'unhinged' from the fundamentals of the economy. In terms of anchoring arising from lower volatility of the own shock impinging on long-

\footnotetext{
${ }^{14}$ Cogley, Primiceri, and Sargent (2008) use similar posterior probabilities to highlight post-war changes in inflation persistence.

${ }^{15}$ This basic notion of 'anchoring' has been used in various studies of the responsiveness of farforward nominal bond yields and inflation compensation to news on inflation and other economic indicators. See, for example, Gurkaynak, Sack, and Swanson (2005), Gurkaynak, Levin, and Swanson (2006), and Jochmann, Koop, and Potter (2008).
} 
term expectations, there has been a clear and substantial decline - so in this respect, expectations are much better anchored at the end of the sample.

A logical factor driving the change in the variance shares for long-term expectations is monetary policy. A shift to a policy that responds more systematically to observable macroeconomic data and communicates in a more transparent manner may potentially influence inflation expectations. In the current setting, a more systematic monetary policy would result in a decline in the overall volatility of the orthogonalized shock to the federal funds rate, as well as a decline in its relative volatility. A decline in relative volatility will reduce the variance share of the federal funds rate attributable to its own shock. In general, these changes would provide a better understood mapping between observable macroeconomic data and the federal funds rate, a factor that could help survey participants form long-term inflation expectations. Granted, perfectly anchored expectations should not move in response to any data. However, survey-based measures capture expected average inflation over the next ten years, so a shock that is expected to have a persistent effect on the economy could potentially move such measures. ${ }^{16}$

The top right panel of Figure 2 indicates a rapid decline in the standard deviation of the own shock to the federal funds rate throughout the 1980s, after which it roughly stabilizes at a level that is about 75 percent below its level at the start of the sample. Tables 1 and 2 then document the decline in the variance share for the federal funds rate attributable to own shocks. For example, the variance share of own shocks at a five-year horizon at the start of the sample is 47 percent, implying that roughly half of the movement in the federal funds rate was not due to movements in inflation, the CFNAI or inflation expectations. This share falls to 21 percent at the end of the sample, indicating a closer connection between movements in the data and the federal funds rate. The fall in the own share corresponds to a rise in the shares attributable to inflation and the CFNAI, rather than expectations. Conditioning on volatilities at the beginning of the sample, Table 1 reports that 7 percent of the variance in the federal funds rate at a five-year horizon is attributable to innovations in inflation. This share rises to 27 percent conditional on volatilities at the end of the sample. Table 3 indicates this change is significant at the 10 percent level. Also, a comparison of Tables 1 and 2 shows the rise in the variance share attributable to inflation holds for the decompositions at the one- and two-year horizons. The lower-right panel in Figure 3 reiterates these points, showing the changes in the variance shares over the sample period for the two-year horizon.

\footnotetext{
${ }^{16}$ The extent to which current shocks that are perceived to be persistent affect long-term expectations depends on the central banks mandate regarding price stability. A perfectly credible policy that is expected to 'undo' past mistakes by engineering a period of disinflation, such as a price-level target, will imply that current shocks that have a persistent effect will not affect measures of average inflation over a sufficiently long horizon. However, given the Federal Reserve does not have a formal inflation target, let alone a price level target, it is unlikely survey participants expected deviations from some implicit inflation target to be undone in the future.
} 
The shift towards a more systematic monetary policy occurs primarily throughout the 1980s, when the variance of the innovation to the federal funds rate fell both in absolute terms (Figure 2) and relative terms (Figure 3). This dynamic is basically the same for long-term expectations, however, the timing differs. The larger changes in the volatility of the innovations to the federal funds rate occur before the changes in the volatility of the innovation to expectations. Figure 2 shows the decline in absolute volatility occurs more rapidly for the federal funds rate than for long-term expectations. Figure 3 then shows the relative shift away from own shocks also occurs sooner for the federal funds rate than for the expectations measures. Thus, one interpretation of the tighter link between inflation and inflation expectations is that more systematic behavior in monetary policy fed through to more systematic adjustment of long-term expectations by forecasters.

\section{Robustness Checks}

To establish the robustness of our baseline result that the variance of long-term expectations attributable to movements in inflation has risen over the past twenty-five years, in this section we consider results from two modifications of the baseline VAR with stochastic volatility. First, we augment the VAR with stochastic volatility to include disaggregated price data on food and energy. This allows us to assess the extent to which the shift in the variance in long-term expectations has been driven by inflation in core prices or food and energy prices. Second, we extend the VAR to include not only stochastic volatility but also time-varying coefficients. To make the exercise tractable, we scale down the model to include only expectations and inflation data.

\subsection{Incorporating Disaggregated Price Data}

The model in this section separates the impact of food and energy price inflation on long-term expectations from the impact of core inflation. ${ }^{17}$ We disaggregate the CPI between a core (ex food and energy) component and a food and energy component, where shocks to either (core or food-energy) may affect long-term expectations differently. We construct food-energy inflation as a weighted average of inflation in the CPI for food and the CPI for energy, using relative importances as weights. In the identification scheme, we use the same ordering as above, with inflation split into the core component that comes before the food-energy component. As before, the model allows time variation in the variance-covariance matrix of innovations $\left(A_{t}\right.$ and $\left.\Sigma_{t}\right)$.

\footnotetext{
${ }^{17}$ Mehra and Herrington (2008) take a similar approach by embedding a commodity price index into a VAR and then assessing the impact that shocks to the index have on short-term inflation expectations.
} 
Figure 4 reports the different measures of the residual standard deviations for each variable. The paths for the volatility in the innovations to short- and longterm expectations, the federal funds rate and economic activity are broadly similar to Figure 2. The volatility of the innovation to food and energy inflation rises sharply beginning in the late 1990s. This rise is concurrent to the rise in volatility of the innovation to total CPI in Figure 2, indicating the innovations to food and price inflation were the primary factors in raising the volatility of total CPI inflation at the end of the sample. Also, Figure 4 shows the volatility of the innovation to the core measure of inflation has risen only modestly over the past 10 years.

The variance share attributable to food and energy price innovations for longterm expectations has also risen in the latter part of the sample. Figure 5 reports the variance shares for the subset of variables related to inflation and expectations at each date. As before, the share attributable to own shocks for long-term expectations has fallen dramatically. The previous model indicated an increasing role for total CPI inflation in explaining movements in long-term expectations. The model with disaggregated data, however, refines the analysis and indicates that it is the movement in the food and energy component that has risen in importance for explaining movements in long-term expectations. The evolution of the shares for short-term expectations is broadly similar to the model just using total CPI inflation, when the shares due to core inflation and food-energy are combined.

The impact of food and energy prices on short-term expectations is broadly similar to the commodity price shocks in Mehra and Herrington (2008). They find in the post1979 period that the relative contribution from commodity price shocks is between 11 to 22 percent, which is substantially lower than the 40 to 50 percent contribution they find in the pre-1979 sample. Tables 4 and 5 report that shocks to food and energy account for anywhere between 1 and 25 percent of variation in short-term expectations, depending on the date and horizon of the decomposition. However, these tables and Figure 5 point out that food and energy price inflation is relatively more important at the end of the sample than at the beginning.

\subsection{Incorporating Time-Varying VAR Coefficients}

The previous sections document the substantial changes in stochastic volatility for each variable. However, each model has time-invariant VAR coefficients. Given that our estimation sample almost entirely consists of the Great Moderation period, and most studies show the bulk of any time variation in coefficients to have occurred prior to the Great Moderation (see, e.g., Cogley, Primiceri, and Sargent (2008)), coefficient stability seems like a reasonable assumption for our sample. However, to ensure changes in volatility are not spuriously reflecting time variation elsewhere in the model, this section allows time variation in both volatilities and the VAR 
coefficients. The additional free parameters and short sample require us (to ensure computational tractability and well-behaved estimates) to scale back the dimension of the model, so the model in this section uses short- and long term expectations and total inflation.

The model specification is as follows

$$
\begin{aligned}
y_{t} & =X_{t}^{\prime} B_{t}+A_{t}^{-1} \Sigma_{t} \varepsilon_{t}, \\
X_{t}^{\prime} & =I_{n} \otimes\left[1, y_{t-1}^{\prime}, \ldots, y_{t-k}^{\prime}\right], \\
\operatorname{Var}\left(\varepsilon_{t}\right) & =I_{n},
\end{aligned}
$$

where $y_{t}=\left[S_{t+40 \mid t}, S_{t+4 \mid t}, \pi_{t}\right]^{\prime}$. The vector $B_{t}$ contains the time-varying VAR coefficients and follows the random walk process

$$
B_{t}=B_{t-1}+n_{t}
$$

where $n_{t} \sim N(0, R)$. The volatility elements of the model follow the same processes as described in section 4.1. The estimation method is basically that of Cogley and Sargent (2005), modified as in Primiceri (2005) to allow time variation in $A_{t}$. In using a 10-year training sample to set elements of the prior, we follow the suggestion of Del Negro (2003) and put an informative Minnesota prior on the training sample coefficients, in the interest of reducing the frequency of explosive draws of the VAR coefficients. We report posterior estimates based on a sample of 5000 draws, obtained by first generating 10,000 burn-in draws and then saving every fifth draw from another 25,000 draws.

While we omit details in the interest of brevity, the estimates of the model show that there have been some small changes over time in the VAR coefficients. For example, in the equation for long-run expectations, the posterior mean of the sum of coefficients on lagged inflation has risen from about zero in the first few years of the sample to nearly .04 (the corresponding 15th percentile is about .01) for the past decade.

However, such changes in coefficients seem to be sufficiently small as to be dwarfed by the larger changes in residual volatilities: allowing time variation in coefficients does little to change the variance decompositions obtained with constant VAR parameters. Figure 6 reports the time series of variance shares estimated with the trivariate model with TVP and stochastic volatility, at a horizon of two years. The share at each period $t$ is a function of the VAR coefficients in $t, A_{t}$, and $\Sigma_{t}$. In this model, clearly, the share of variation in long-run expectations due to 'own' shocks has fallen sharply, while the share due to CPI inflation shocks has risen sharply. The shift in shares begins in the late 1990s, even though the decline in the volatility of expectations (not shown for the three variable model) began in the mid-1980s. Therefore, the message from the smaller model with TVP is the same as the message from the baseline model with constant VAR coefficients: there has been a decline in the share of total variance attributable to 'own' shocks for long-term expectations. 


\section{Conclusions}

This paper documents two changes in the behavior of survey-based measures of longterm inflation expectations over the past twenty-five years. First, we document the marked decline in the volatility of the orthogonal innovation impinging on long-term expectations - that is, the volatility of the 'own' shock to long-term expectations has fallen substantially. In our empirical setting, we interpret own shocks to expectations as reflecting unforecastable movements in survey-measures arising from omitted fundamentals, rather than sunspot innovations. Importantly, these omitted variables may include factors such as central bank communication policies, which are likely important in influencing long-term expectations, but are difficult to measure and formally incorporate into a model. Second, the variance share attributable to observable macroeconomic data, such as actual inflation, has risen. Until the mid-1990s, roughly 75 percent of the variance in long-term expectations was due to own shocks. In 2008, the own shock contribution fell to 25 percent, whereas the contribution from actual inflation increased to over 50 percent. Our benchmark framework uses a VAR with a time-varying variance-covariance matrix, though we show our results our robust to alternative specifications. 


\section{References}

Benati, Luca (2008), "The 'Great Moderation' in the United Kingdom," Journal of Money, Credit, and Banking, v.40, pp. 121-147.

Benati, Luca, and Paolo Surico (2008), "Evolving U.S. Monetary Policy and the Decline of Inflation Predictability," Journal of the European Economic Association, v.6, pp. 634-646.

Bernanke, Ben S. Jean Boivin, and Piotr Eliasz (2005), "Measuring Monetary Policy: A Factor Augmented Vector Autoregressive (FAVAR) Approach," Quarterly Journal of Economics, v.120.

Canova, Fabio, and Luca Gambetti (2008), "Do Expectations Matter? The Great Moderation Revised," manuscript, Universitat Pompeu Fabra.

Canova, Fabio, Luca Gambetti and Evi Pappa (2007), "The Structural Dynamics of Output Growth and Inflation: Some International Evidence," The Economic Journal.

Carroll, Christopher D. (2003), "Macroeconomic Expectations of Households and Professional Forecasters," Quarterly Journal of Economics, v.118, pp. 269-298.

Choy, Keen Meng, Kenneth Leong, and Anthony S. Tay (2006), "Non-Fundamental Expectations and Economic Fluctuations: Evidence from Professional Forecasts," Journal of Macroeconomics, v.28, pp. 446-460.

Cogley, Timothy, Giorgio E. Primiceri, and Thomas J. Sargent (2008), "Inflation-Gap Persistence in the U.S.," forthcoming, American Economic Journal: Macroeconomics.

Cogley, Timothy, and Thomas J. Sargent (2005), "Drifts and Volatilities: Monetary Policies and Outcomes in the post WWII US," Review of Economic Dynamics, v.8, pp. 262-302.

Del Negro, Marco (2003), "Discussion of Cogley and Sargent's 'Drifts and Volatilities: Monetary Policy and Outcomes in the Post WWII U.S.'," Federal Reserve Bank of Atlanta Working Paper 2003-26.

Gurkaynak, Refet S., Andrew T. Levin, and Eric T. Swanson (2006), "Does Inflation Targeting Anchor Long-Run Inflation Expectations? Evidence from Long-Term Bond Yields in the US, UK, and Sweden," CEPR Working Paper 5806.

Gurkaynak, Refet S., Brian Sack, and Eric Swanson (2005), "The Sensitivity of LongTerm Interest Rates to Economic News: Evidence and Implications for Macroe- 
conomic Models," American Economic Review, v.95, pp. 425-436.

Jochmann, Markus, Gary Koop, and Simon M. Potter (2008), "Modeling the Dynamics of Inflation Compensation," manuscript, Federal Reserve Bank of New York.

Kozicki, Sharon, and Peter A. Tinsley (2001), "Shifting Endpoints in the Term Structure of Interest Rates," Journal of Monetary Economics, v.47, pp. 613-652.

Leduc, Sylvain, Keith Sill, and Tom Stark (2007), "Self-Fulfilling Expectations and the Inflation of the 1970s: Evidence from the Livingston Survey," Journal of Monetary Economics, v.54, pp. 433-459.

Mehra, Yash P. and Christopher Herrington (2008), "On the Sources of Movements in Inflation Expectations: A Few Insights from a VAR Model," Economic Quarterly, Federal Reserve Bank of Richmond, v.94, pp. 121-146.

Primiceri, Giorgio (2005), "Time Varying Structural Vector Autoregressions and Monetary Policy," Review of Economic Studies, v.72, pp. 821-852.

Stock, James H., and Mark W. Watson (1999), "Forecasting Inflation," Journal of Monetary Economics, v.44, pp. 293-335.

Sims, Christopher, and Tao Zha (2006), "Were There Regime Switches in US Monetary Policy?" American Economic Review, v.96, pp. 54-81. 


\begin{tabular}{|l|ccccc|}
\hline \hline & \multicolumn{5}{|c|}{ shock to: } \\
\hline response of: & EXP10YR & EXP1YR & CPI & CFNAI & FFR \\
\hline \hline & \multicolumn{5}{|c|}{ horizon = 1 year } \\
\hline EXP10YR & $75(15.9)$ & $8(8.1)$ & $6(7.0)$ & $2(3.1)$ & $9(11.0)$ \\
EXP1YR & $22(13.8)$ & $55(17.5)$ & $5(5.9)$ & $7(7.1)$ & $11(11.6)$ \\
CPI & $8(7.5)$ & $17(13.1)$ & $45(19.1)$ & $8(8.3)$ & $23(17.3)$ \\
CFNAI & $9(7.9)$ & $14(12.6)$ & $11(10.5)$ & $43(18.7)$ & $23(18.7)$ \\
FFR & $7(7.8)$ & $4(5.5)$ & $2(3.5)$ & $17(14.3)$ & $70(18.6)$ \\
\hline \multicolumn{5}{|c|}{ horizon = 2 years } \\
\hline EXP10YR & $63(20.5)$ & $9(10.1)$ & $9(9.9)$ & $3(4.5)$ & $16(17.2)$ \\
EXP1YR & $25(15.3)$ & $42(18.1)$ & $5(5.9)$ & $10(9.8)$ & $19(17.1)$ \\
CPI & $8(7.1)$ & $18(13.2)$ & $38(18.4)$ & $9(8.8)$ & $27(18.3)$ \\
CFNAI & $7(6.7)$ & $17(13.7)$ & $11(9.9)$ & $33(17.6)$ & $32(22.2)$ \\
FFR & $9(9.0)$ & $6(7.3)$ & $5(6.6)$ & $30(17.7)$ & $50(21.0)$ \\
\hline \multicolumn{5}{|c|}{ horizon $=\mathbf{5}$ years } \\
\hline EXP10YR & $49(22.8)$ & $14(14.7)$ & $10(11.7)$ & $6(8.3)$ & $21(19.3)$ \\
EXP1YR & $27(16.7)$ & $34(17.6)$ & $6(7.5)$ & $10(10.4)$ & $22(18.8)$ \\
CPI & $8(7.1)$ & $18(13.3)$ & $35(17.7)$ & $11(9.6)$ & $28(18.6)$ \\
CFNAI & $7(6.3)$ & $17(13.4)$ & $11(9.8)$ & $32(17.3)$ & $34(21.9)$ \\
FFR & $10(9.5)$ & $9(10.1)$ & $7(8.3)$ & $27(16.7)$ & $47(21.3)$ \\
\hline
\end{tabular}

Table 1: Variance decomposition from baseline VAR with stochastic volatility, using total CPI inflation, 1982:Q3 volatilities. [NOTE: Entries are posterior mean estimates of variance shares, in percent terms, with posterior standard deviations in parentheses.] 


\begin{tabular}{|l|ccccc|}
\hline \hline & \multicolumn{5}{|c|}{ shock to: } \\
\hline response of: & EXP10YR & EXP1YR & CPI & CFNAI & FFR \\
\hline \hline & \multicolumn{5}{|c|}{ horizon = 1 year } \\
\hline EXP10YR & $33(19.9)$ & $11(10.0)$ & $48(22.0)$ & $3(4.2)$ & $5(6.9)$ \\
EXP1YR & $6(5.9)$ & $55(18.1)$ & $28(17.9)$ & $8(7.7)$ & $4(4.6)$ \\
CPI & $1(1.1)$ & $6(6.2)$ & $87(8.9)$ & $3(4.1)$ & $3(3.9)$ \\
CFNAI & $2(3.0)$ & $12(11.1)$ & $34(19.9)$ & $44(20.0)$ & $8(8.6)$ \\
FFR & $2(3.1)$ & $10(10.3)$ & $10(12.3)$ & $37(20.4)$ & $42(20.8)$ \\
\hline \multicolumn{5}{|c|}{ horizon = 2 years } \\
\hline EXP10YR & $24(18.4)$ & $11(11.5)$ & $53(23.7)$ & $4(5.7)$ & $8(10.6)$ \\
EXP1YR & $7(7.2)$ & $44(18.5)$ & $29(18.2)$ & $12(10.9)$ & $7(8.4)$ \\
CPI & $1(1.1)$ & $7(7.1)$ & $83(10.6)$ & $4(5.0)$ & $4(4.7)$ \\
CFNAI & $2(2.6)$ & $15(12.7)$ & $35(19.5)$ & $36(18.6)$ & $12(11.8)$ \\
FFR & $3(3.8)$ & $9(10.2)$ & $19(17.3)$ & $46(20.8)$ & $24(16.3)$ \\
\hline \multicolumn{5}{|c|}{ horizon $=\mathbf{5}$ years } \\
EXP10YR & $17(16.2)$ & $15(15.8)$ & $50(24.6)$ & $8(10.5)$ & $9(11.8)$ \\
EXP1YR & $8(8.2)$ & $36(18.3)$ & $33(19.8)$ & $13(11.9)$ & $9(10.2)$ \\
CPI & $1(1.2)$ & $8(7.8)$ & $81(12.1)$ & $6(6.2)$ & $5(5.2)$ \\
CFNAI & $2(2.4)$ & $16(12.7)$ & $36(19.4)$ & $35(18.5)$ & $12(11.8)$ \\
FFR & $3(4.2)$ & $12(11.4)$ & $27(19.8)$ & $38(20.2)$ & $21(15.1)$ \\
\hline
\end{tabular}

Table 2: Variance decomposition from baseline VAR with stochastic volatility, using total CPI inflation, 2008:Q2 volatilities. [NOTE: Entries are posterior mean estimates of variance shares, in percent terms, with posterior standard deviations in parentheses.] 


\begin{tabular}{|l|ccccc|}
\hline \hline & \multicolumn{5}{|c|}{ prob(2008:Q2 share > 1982:Q3 share) } \\
\hline & EXP10YR & EXP1YR & CPI & CFNAI & FFR \\
\hline response of: & \multicolumn{5}{|c|}{ horizon = 1 year } \\
\hline EXP10YR & .051 & .665 & .991 & .650 & .267 \\
EXP1YR & .072 & .493 & .972 & .554 & .128 \\
CPI & .02 & .140 & .983 & .199 & .019 \\
CFNAI & .107 & .426 & .893 & .521 & .093 \\
FFR & .153 & .725 & .830 & .819 & .133 \\
\hline & \multicolumn{5}{|c|}{ horizon $=\mathbf{2}$ years } \\
\hline EXP10YR & .067 & .570 & .989 & .603 & .200 \\
EXP1YR & .086 & .556 & .976 & .584 & .133 \\
CPI & .022 & .159 & .984 & .220 & .019 \\
CFNAI & .113 & .474 & .923 & .546 & .082 \\
FFR & .129 & .648 & .860 & .751 & .122 \\
\hline & .072 & .535 & .983 & .596 & .164 \\
EXP10YR & .089 & .553 & .978 & .596 & .133 \\
EXP1YR & .025 & .180 & .983 & .239 & .023 \\
CPI & .113 & .478 & .929 & .552 & .081 \\
CFNAI & .136 & .600 & .906 & .691 & .105 \\
FFR & \multicolumn{5}{|c}{} \\
\hline
\end{tabular}

Table 3: Posterior probabilities of changes in forecast error variance shares from baseline VAR with stochastic volatility. 


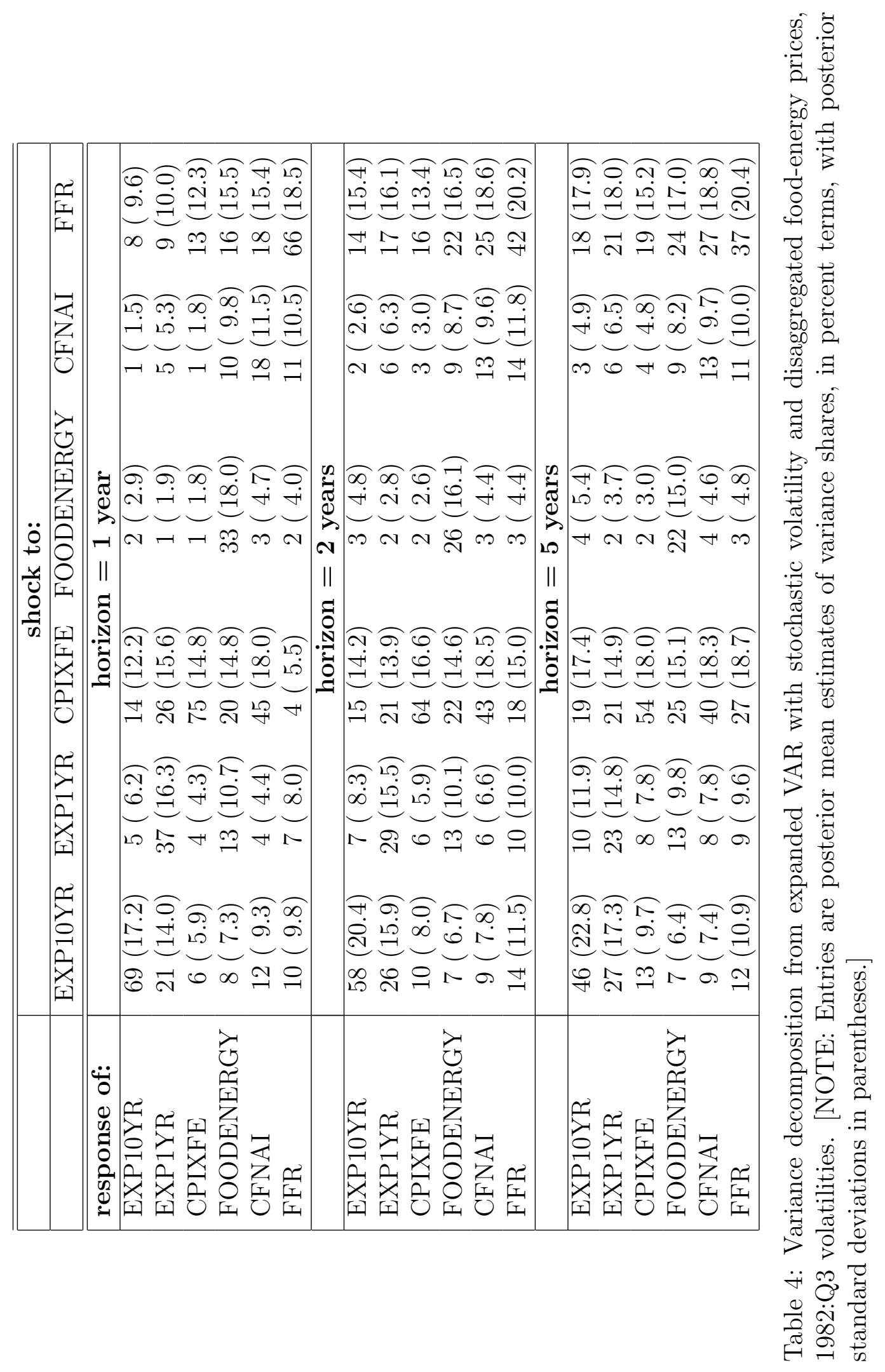




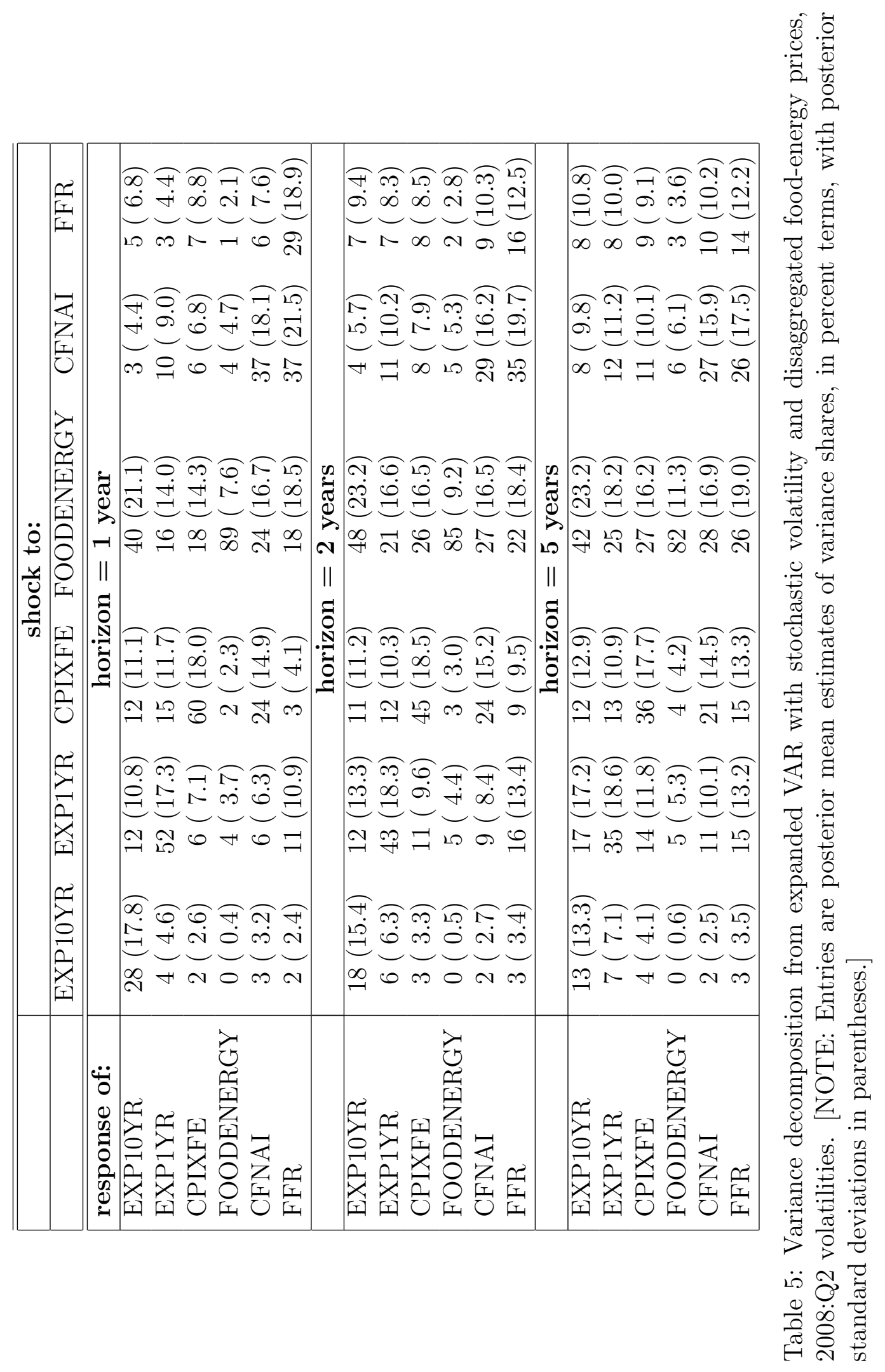




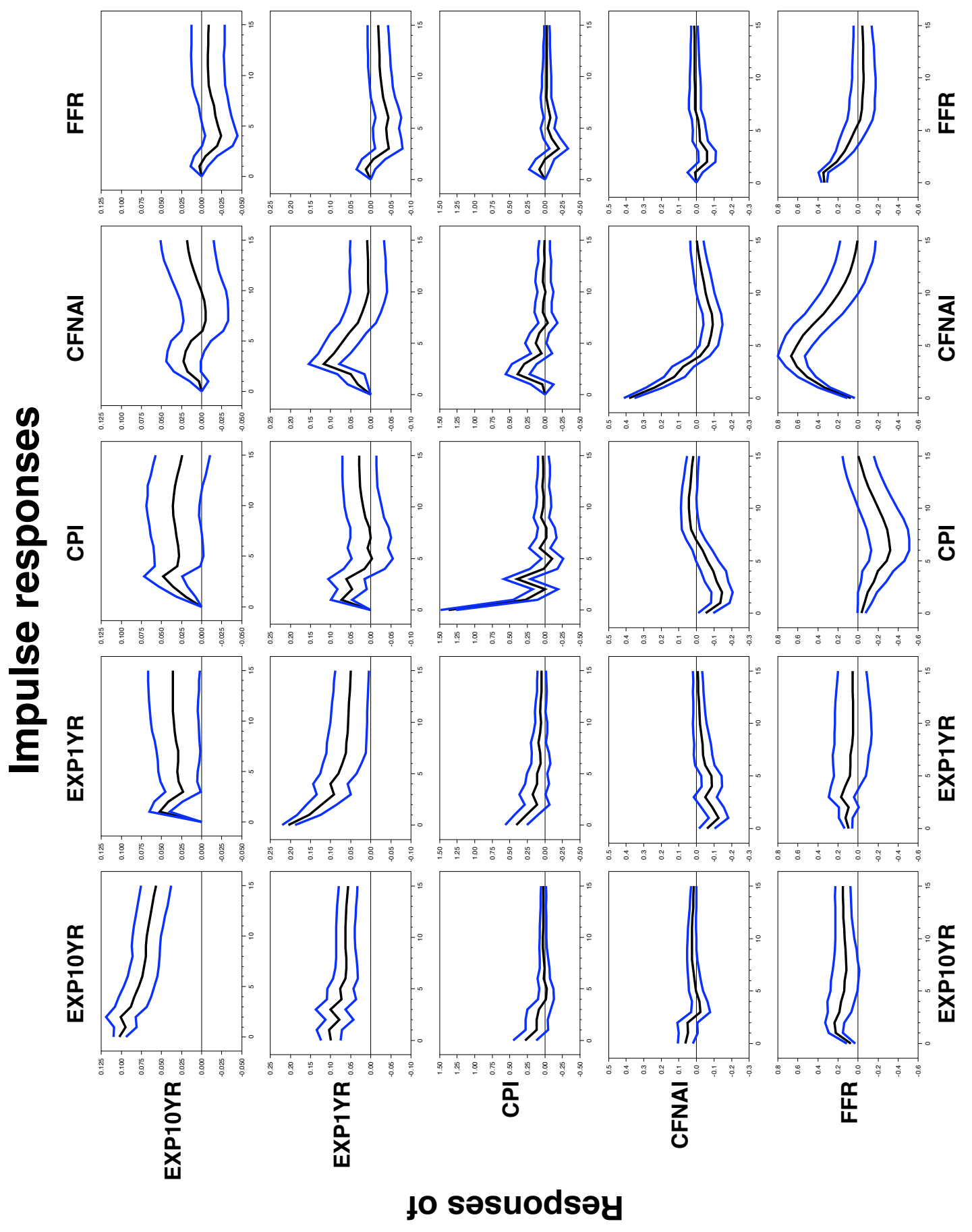

Figure 1: Benchmark VAR - Impulse Responses 

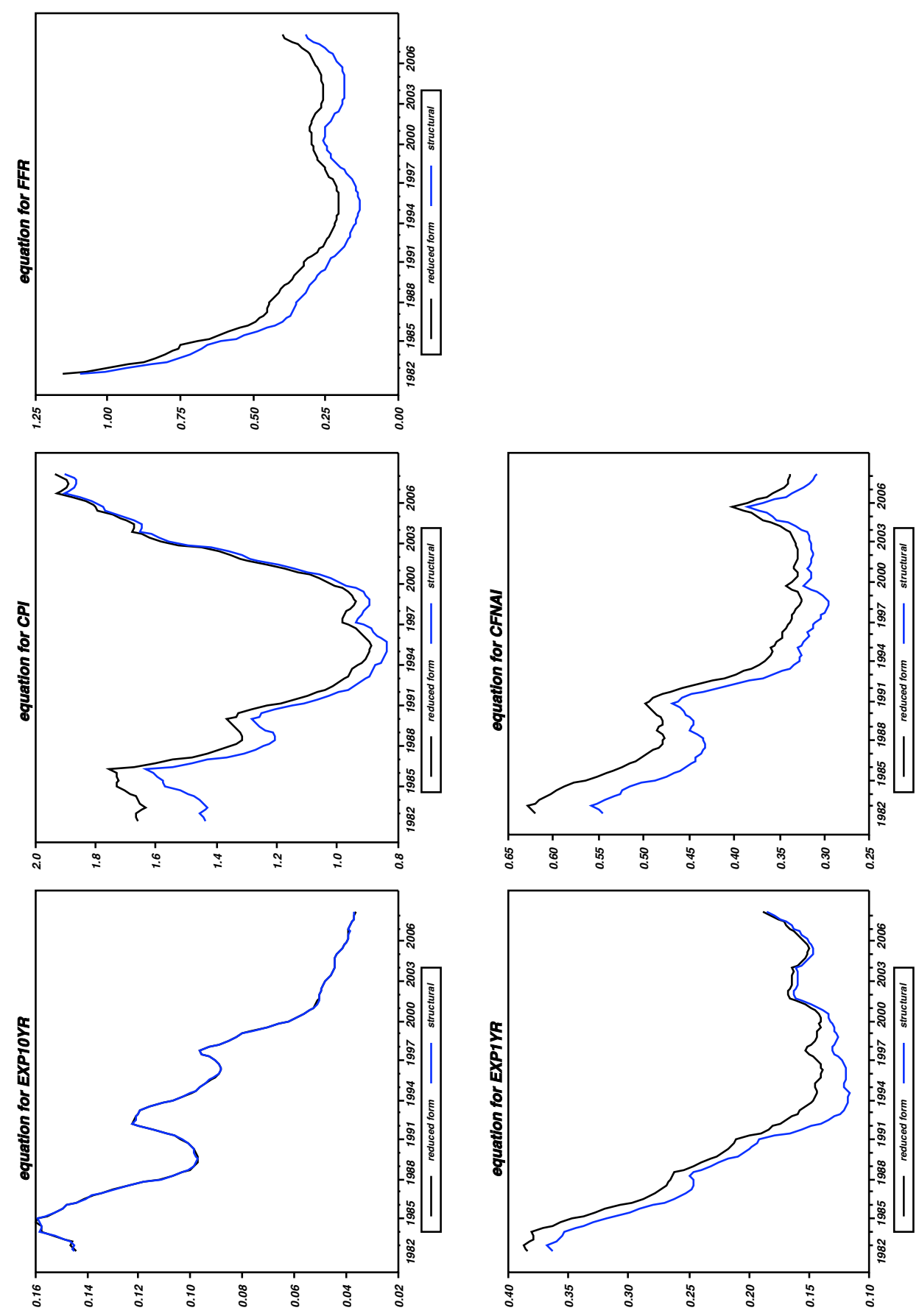

Figure 2: VAR with Stochastic Volatility - Residual Standard Deviations 


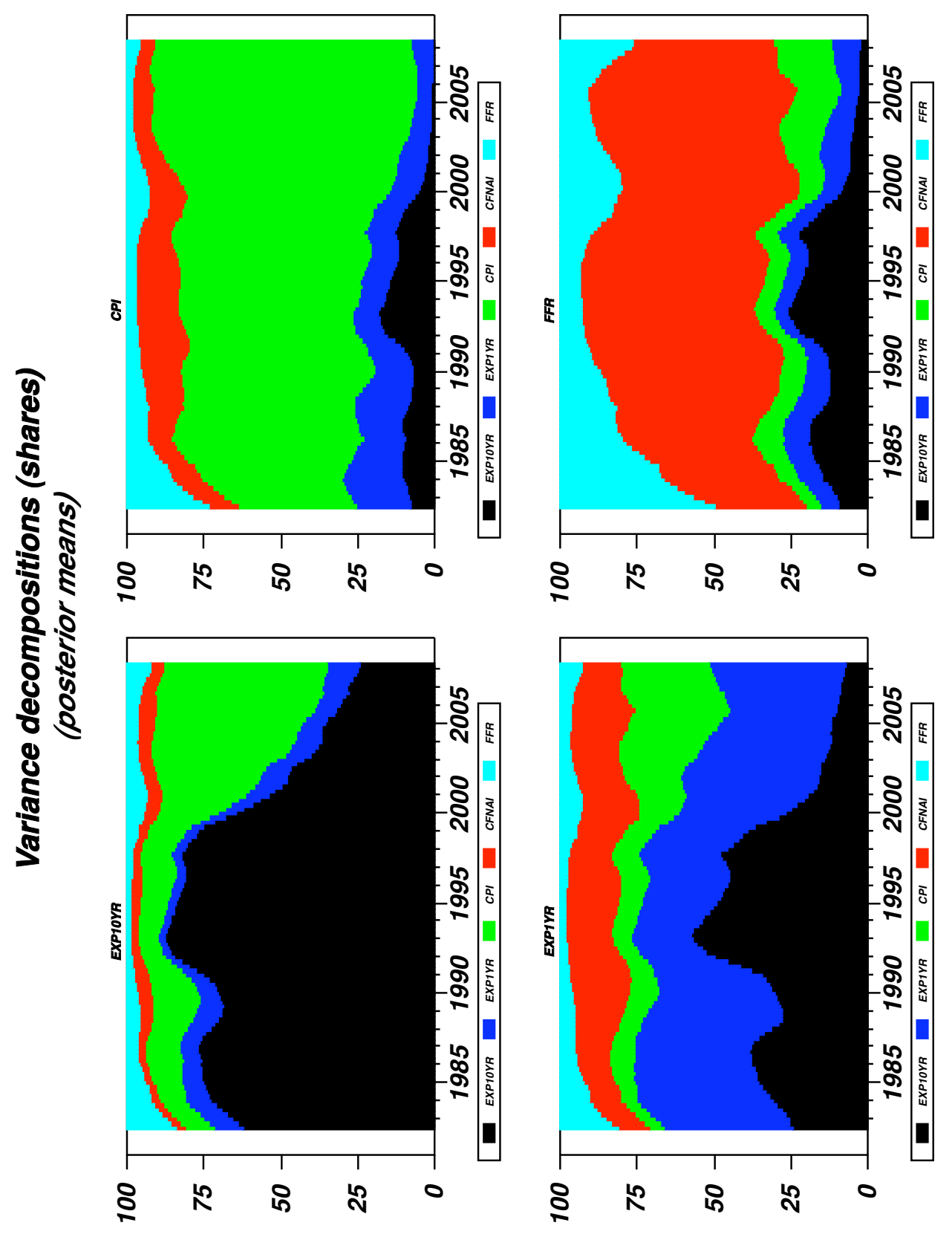

Figure 3: VAR with Stochastic Volatility - Variance Shares (2-year Forecast Horizon) 

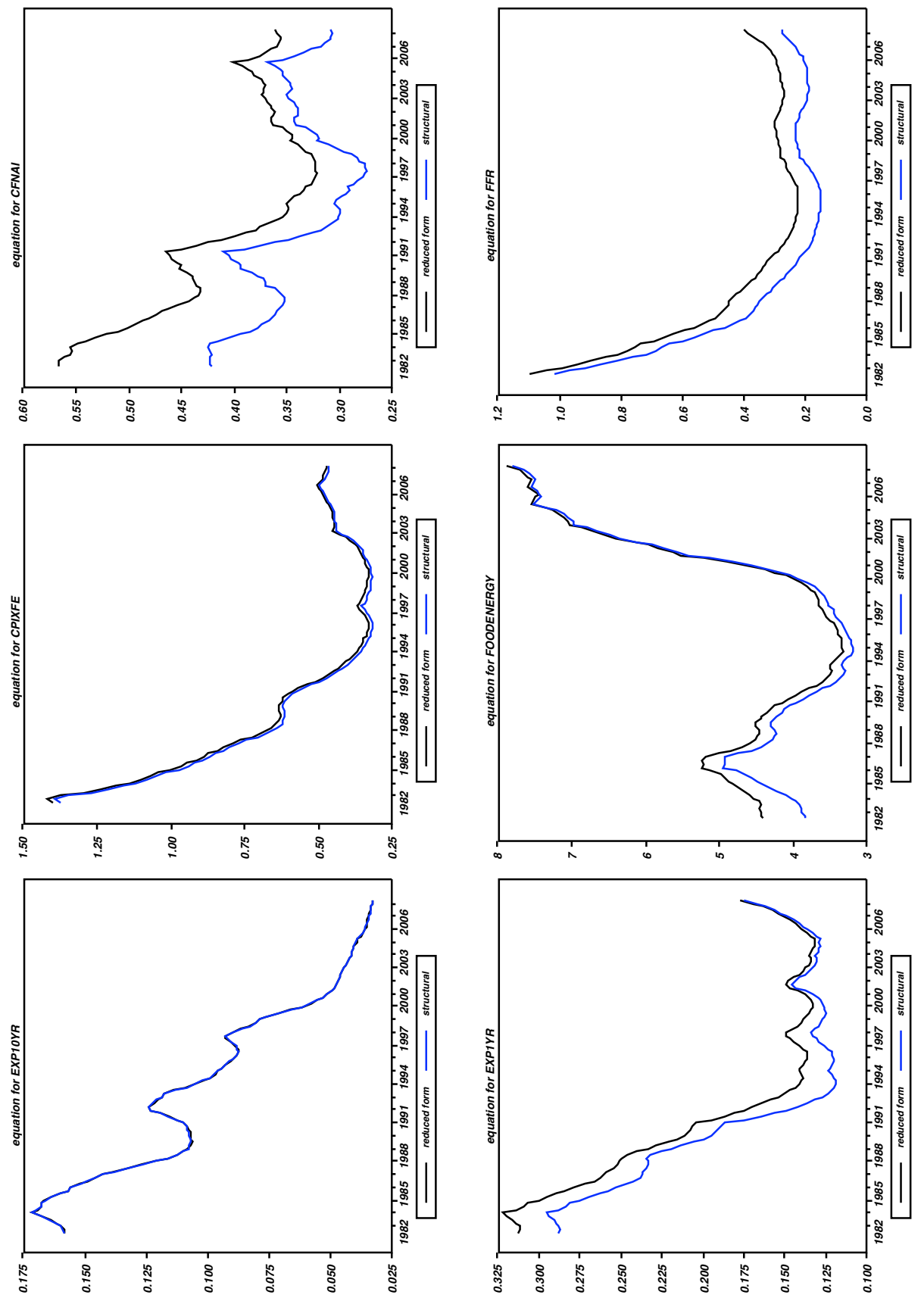

Figure 4: VAR with Stochastic Volatility and Disaggregated Food and Energy Price Data - Residual Standard Deviations 

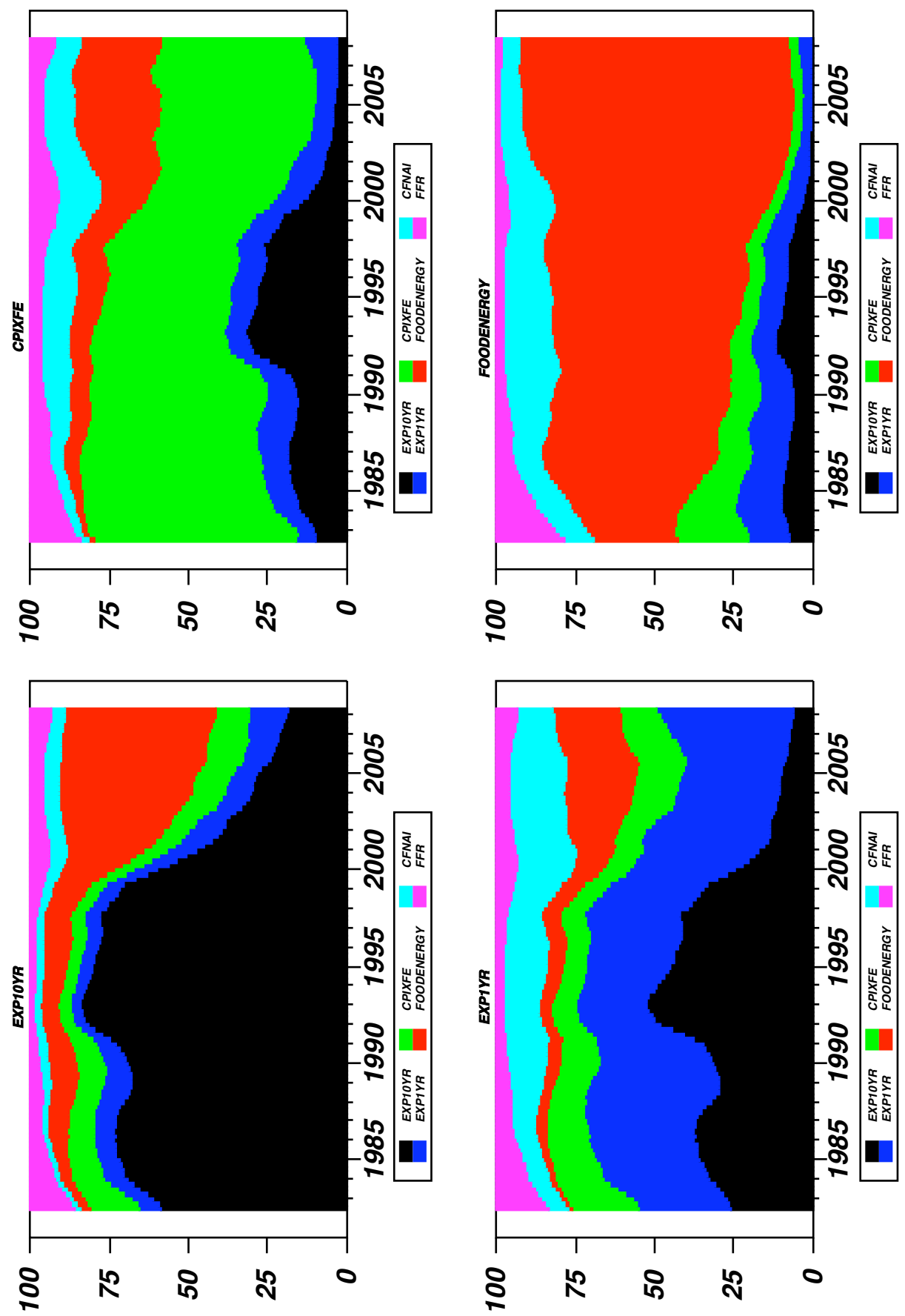

Figure 5: VAR with Stochastic Volatility and Disaggregated Food and Energy Price Data - Variance Shares (2-year Forecast Horizon) 

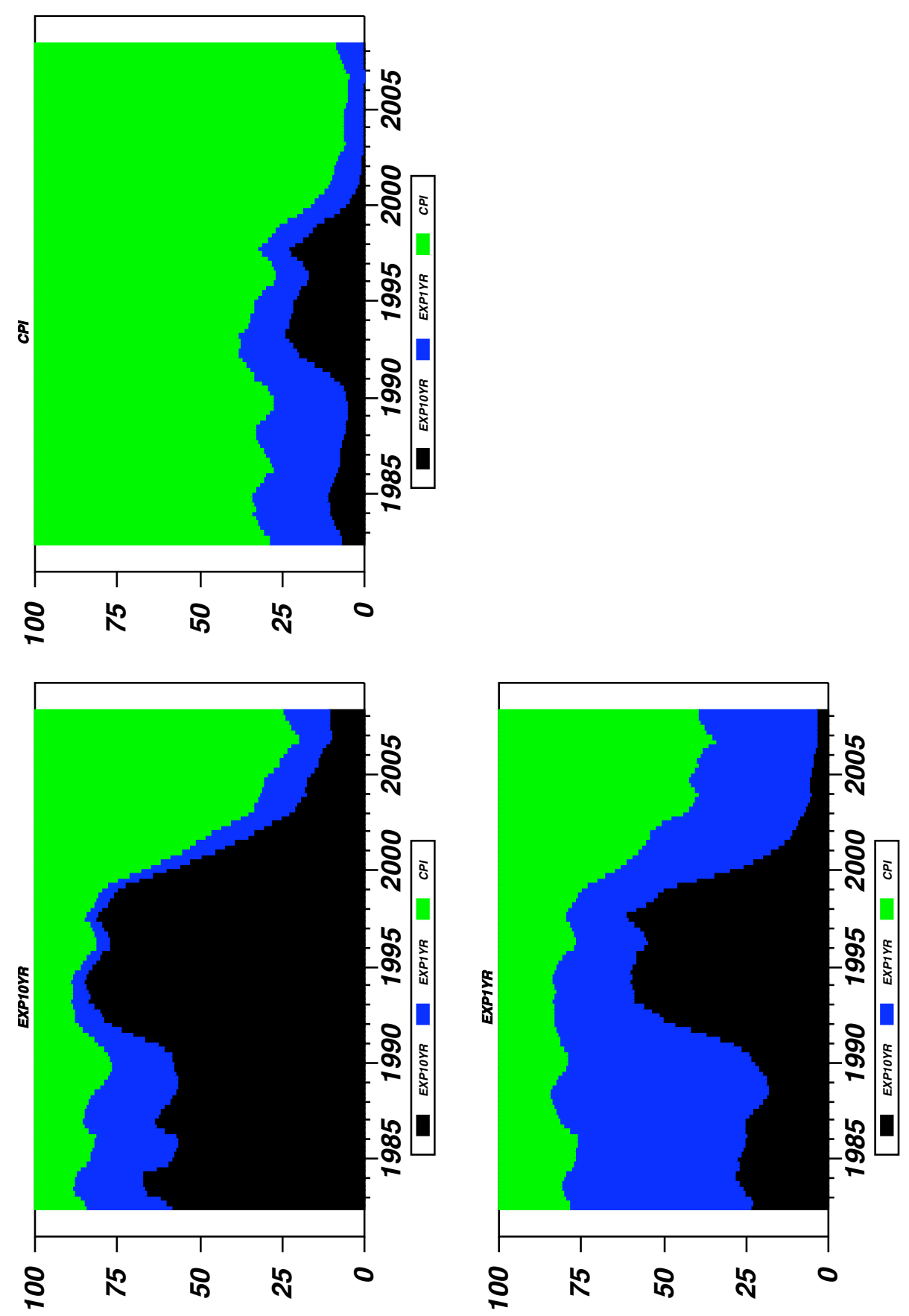

Figure 6: Time-Varying Parameter VAR with Stochastic Volatility - Variance Shares (2-year Forecast Horizon) 